1 Universidade Federal do Rio de Janeiro (UFRJ) - Rio de Janeiro (RJ), Brasil. emmanuelaneves@yahoo. com.br

2 Universidade de São Paulo (USP) - São Paulo (SP), Brasil.

\section{Intersetorialidade e Atenção Básica à Saúde: a atenção a mulheres em situação de violência}

\author{
Intersectoral collaboration and Primary Health Care: attention to \\ women in situation of violence
}

Emmanuela Gonsalves', Lilia Blima Schraiber²

DOI: $10.1590 / 0103-1104202113102$

\begin{abstract}
RESUMO A atuação em rede intersetorial constitui um desafio para a atenção a mulheres em situação de violência de gênero. A pesquisa qualitativa de que trata este artigo se utilizou de um estudo de caso para investigar as possibilidades de construção de uma rede intersetorial entre a Atenção Básica à Saúde e serviços especializados no atendimento àquelas mulheres, especificamente na região Centro do Rio de Janeiro. Os dados levantados por meio de entrevistas semiestruturadas e observação dos serviços foram submetidos à análise de conteúdo. Para o presente artigo, analisaram-se: a trama de serviços atualmente existente; a relação entre atenção básica e serviços especializados; e o lugar da atenção básica na atenção integral a mulheres em situação de violência. Os resultados apontam que há tendencialmente potencial para a construção de uma assistência em rede, ainda que diversos obstáculos institucionais e da cultura assistencial de cada tipo de serviço gerem uma configuração ainda pouco integrada enquanto uma rede. Mesmo assim, os resultados também mostram que os centros de referência para a atenção em violência de gênero são os serviços, atualmente, com maior potencial para atuar em rede, especialmente na relação com o setor saúde.
\end{abstract}

PALAVRAS-CHAVE Atenção Primária à Saúde. Violência de gênero. Assistência integral à saúde.

ABSTRACT Actions that happen through an intersectoral network are challenging for the care of women in situations of gender violence. The qualitative research developed in this article used a case study to investigate the possibilities of building an intersectoral network between Primary Health Care and specialized services in the care of those women, specifically in the central region of Rio de Janeiro. Data collected through semistructured interviews and observation of the services were submitted to content analysis. In this article we analyzed: the network of services currently in place; the relationship between primary care and specialized services; and the place of primary care within the comprehensive care of women in situations of violence. The results indicate that there is a tendency towards building a networked assistance, even though several institutional obstacles and the culture of assistance work in each type of service generate a still scarcely integrated configuration as a network. Even so, the results also show that the reference centers for assistance to gender violence are currently the services with the greatest potential to act in a network, especially in relation to the health sector.

KEYWORDS Primary Health Care. Gender-based violence. Comprehensive health care. 


\section{Introdução}

Este artigo aborda a violência de gênero contra mulheres. Considera-se gênero, conforme Scott ${ }^{1}$ e corroborado por Safioti \& Almeida ${ }^{2}$ e Heise et al. ${ }^{3}$, como um conjunto objetivo de referências que estrutura a percepção e a organização material de toda a vida social, sendo o núcleo essencial dessa definição baseado na conexão integral entre duas proposições: o gênero é um elemento constitutivo de relações sociais baseado nas diferenças percebidas entre os sexos, e o gênero é uma forma primeira de significar as relações de poder, resultando na desigualdade de gênero, construção da dimensão relacional, no exercício das feminilidades/masculinidades, que produz e reproduz a desigualdade de poder, com o domínio do masculino. Nestes termos, entende-se violência de gênero como o fenômeno sociocultural e histórico que conforma comportamentos masculinos de aculturação da mulher em sua condição de subalternidade, prevenindo mudanças e reproduzindo o domínio do masculino, ou conforma comportamentos masculinos que, em efetivas situações sociais de ameaças de ruptura da dominação tradicional, constituem tentativas de retomada pela força daquela hierarquia de dominação ${ }^{4}$.

Reconhecendo-se que a violência de gênero traz grandes impactos na saúde das mulheres e baseando-se o presente estudo nos marcos dos direitos humanos, direito à saúde e direitos das mulheres a uma atenção integral à sua saúde ${ }^{5}$, apresenta-se uma análise sobre as relações estabelecidas entre Unidades Básicas de Saúde (UBS) e serviços especializados no atendimento a mulheres em situação de violência no que se refere às potencialidades de construção de uma rede intersetorial para a atenção à violência de gênero, na região Centro da cidade do Rio de Janeiro, a partir de dados coletados em pesquisa de doutorado.

Ao se considerar que, como apresentado em diversos estudos ${ }^{\mathbf{4}, 6-9}$, a violência contra as mulheres constitui um problema de ordens social, cultural, de direitos humanos e de saúde pública, que demanda uma atuação multiprofissional, interdisciplinar e intersetorial, em que as ações profissionais e os serviços se complementam na atenção integral ao enfrentamento da violência, importa compreender como os diferentes setores sociais se articulam na atuação junto a mulheres em situação de violência, verificando se existem potencialidades de atuação em rede, bem como investigar empiricamente que dados referendam essas potencialidades ou seus obstáculos.

Reconhecida mundialmente como uma questão de saúde pública ${ }^{9}$, a problemática da violência de gênero conquista espaço no campo da saúde coletiva com pesquisas, propostas de intervenção e políticas específicas para lidar com o fenômeno ${ }^{10}$, que destacam, inclusive, que a saúde constitui uma porta de entrada privilegiada para assistência às mulheres em situação de violência ${ }^{6-8}$.

Para a presente reflexão, consideramos central a discussão sobre o princípio da integralidade. Pensada da perspectiva dos processos de trabalho em saúde, a integralidade, enquanto trabalho que responde às necessidades sociais em saúde, remete a uma atuação multiprofissional, interdisciplinar e intersetorial11. A intersetorialidade ganha, assim, articulações necessárias com a interdisciplinaridade e a atuação em equipe multiprofissional, permitindo-se pensá-la sob o mesmo referencial que articula a complexidade de trabalhos parcelares especializados também internamente ao campo da saúde.

Considerando, portanto, tal complexidade e a incompletude institucional representada pela atenção segmentar de cada setor para lidar sozinho com a questão, a Secretaria de Políticas para as Mulheres da Presidência da República (SPM-PR) publicou o documento 'Rede de enfrentamento à violência contra as mulheres' que estabelece diretrizes da intersetorialidade. Ao considerar que rede de atendimento às mulheres em situação de violência se refere,

[...] ao conjunto de ações e serviços de diferentes setores $[. .$.$] que visam à ampliação e$ 
à melhoria da qualidade do atendimento; à identificação e ao encaminhamento adequado das mulheres em situação de violência e à integralidade e humanização do atendimento ${ }^{\mathbf{1 2}(\mathbf{0 8}) \text {. }}$

Institui que a rede de atendimento inclui serviços especializados e não especializados de atendimento à mulher, subdivididos em quatro áreas principais: justiça, assistência social, saúde e segurança pública.

Em termos do setor saúde, é importante destacar a inclusão da Atenção Básica à Saúde (ABS) como um dos serviços não especializados que atuam na rede de atenção às mulheres em situação de violência. Como porta de entrada preferencial para o Sistema Único de Saúde brasileiro (SUS), a ABS configura-se com a proposta de Estratégia Saúde da Família (ESF), organizando o atendimento já enquanto atenção prestada por uma equipe multiprofissional, composta, no mínimo, de enfermeiro, médico e agentes comunitário, responsáveis por um território específico. Nesse modelo de atenção, a equipe será o primeiro contato da população com os serviços de saúde, devendo estabelecer vínculo com a população adstrita, a partir do qual serão empreendidas ações coletivas e individuais, dentre elas os encaminhamentos para outros serviços e a atenção longitudinal ${ }^{13}$.

O cuidado longitudinal e o estabelecimento do vínculo entre profissional e a mulher atendida propiciam, além da relação mais próxima entre serviço de saúde e comunidade, o cuidado de problemas de saúde mais comuns, muitas vezes relacionados aos impactos da violência de gênero. Assim, estudos têm dado destaque à atenção primária, enquanto setor saúde, para o trabalho junto a mulheres em situação de violência ${ }^{14-16}$.

No sentido de participar a saúde da construção de uma rede de serviços, em estudo que aprofunda o conceito de rede, Schraiber et al. ${ }^{16}$ compreendem que diferentemente de um sistema, a rede estabelece as tramas a partir das necessidades situacionais, é horizontal, não tem uma única porta de entrada ou fluxos pré-estabelecidos e os serviços inseridos em uma determinada rede podem atuar em diferentes redes ao mesmo tempo. Vale destacar que uma rede é sempre plástica, não obedece rigidamente a fluxogramas, nem estruturas preestabelecidas. Ela se recompõe no tempo e no espaço. Uma rede se estrutura a partir de 'princípios organizadores nucleares', são eles: a relação entre as ações profissionais; a comunicação entre os profissionais; e a interação entre os serviços. Desta forma, é necessário que haja uma integração assistencial para a formação de uma rede.

Esse estudo ainda chama a atenção para o fato de que, se os serviços atuarem como um conjunto, ainda que não necessariamente integrado, constituirão não uma rede, mas uma trama de serviços. Assim, trama se refere a um agrupamento de serviços que podem ter algumas ações articuladas, mas esse aspecto é insuficiente para construir uma atenção integral, que requer a existência de um projeto assistencial que seja comum, compartilhado, entre os serviços envolvidos. E, para tal, a assistência a ser oferecida deve ser construída a partir do diálogo entre os serviços que resulta da interação entre os profissionais; interação voltada a delimitar horizontes assistenciais que lhes sejam comuns ${ }^{16}$.

\section{Metodologia}

O presente artigo baseia-se em pesquisa qualitativa de estudo de caso, que tomou a região Centro do município do Rio de Janeiro para investigar as relações entre a $\mathrm{ABS}$ e os serviços especializados de atendimento às mulheres em situação de violência ${ }^{17}$.

Foram escolhidas três UBS, duas unidades exclusivamente organizadas sob o modelo ESF, sendo que uma delas contava com o suporte do Núcleo de Apoio à Saúde da Família (Nasf) e uma unidade mista, na qual funcionava um Centro Municipal de Saúde (CMS) e uma Clínica da Família (CF). Participaram da pesquisa, também, quatro serviços especializados 
no atendimento às mulheres em situação de violência: dois centros de referência, um serviço policial e um serviço judiciário.

No trabalho de campo, foram realizadas observação institucional e entrevistas com trinta e seis profissionais nos sete serviços. As entrevistas foram gravadas em áudio e transcritas. A observação institucional foi registrada em caderno de campo e usada de modo complementar às entrevistas. A partir da análise de conteúdo ${ }^{\mathbf{1 8}}$ dos dados levantados, foi possível selecionar três categorias de análise: (1) Mapeamento da Trama de serviços; (2) Relação entre ABS e serviços especializados; (3) Lugar da ABS na atenção integral a mulheres em situação de violência. Esclareça-se que se usa a denominação trama para o conjunto de serviços estudados, em substituição à usual denominação de rede, tendo em vista o propósito do estudo de verificar se há de fato atuação em rede ou não, conforme o conceito de rede antes definido ${ }^{16}$.

Para garantir o sigilo das instituições e das entrevistadas, os serviços de saúde foram nomeados como 'UBS1, UBS2 e UBS3' e os especializados como 'Especializado1, Especializado2, Especializado3 e Especializado4'. As entrevistas foram nomeadas a partir das letras 'EE', para as profissionais dos serviços especializados, e 'ES', para as profissionais dos serviços de saúde, seguidos da numeração de 1 a 36, correspondente às entrevistadas.

Aprovada e registrada em dois Comitês de Ética em Pesquisa (CEP) sob os números de Certificado de Apresentação para Apreciação Ética (CAAE) 62891516.7.0000.0065 (Faculdade de Medicina da Universidade de São Paulo) e 62891516.7.3001.5279 (Secretaria Municipal de Saúde do Rio de Janeiro), a ética da pesquisa com seres humanos foi devidamente observada nos termos da legislação brasileira.

\section{Resultados e discussão}

\section{Apresentação da trama de serviços}

Na figura 1, está representado o fluxo de relações estabelecidas entre as UBS e outros serviços para o atendimento a mulheres em situação de violência, de acordo com os dados coletados na pesquisa.

Figura 1. Trama setor Atenção Básica à Saúde

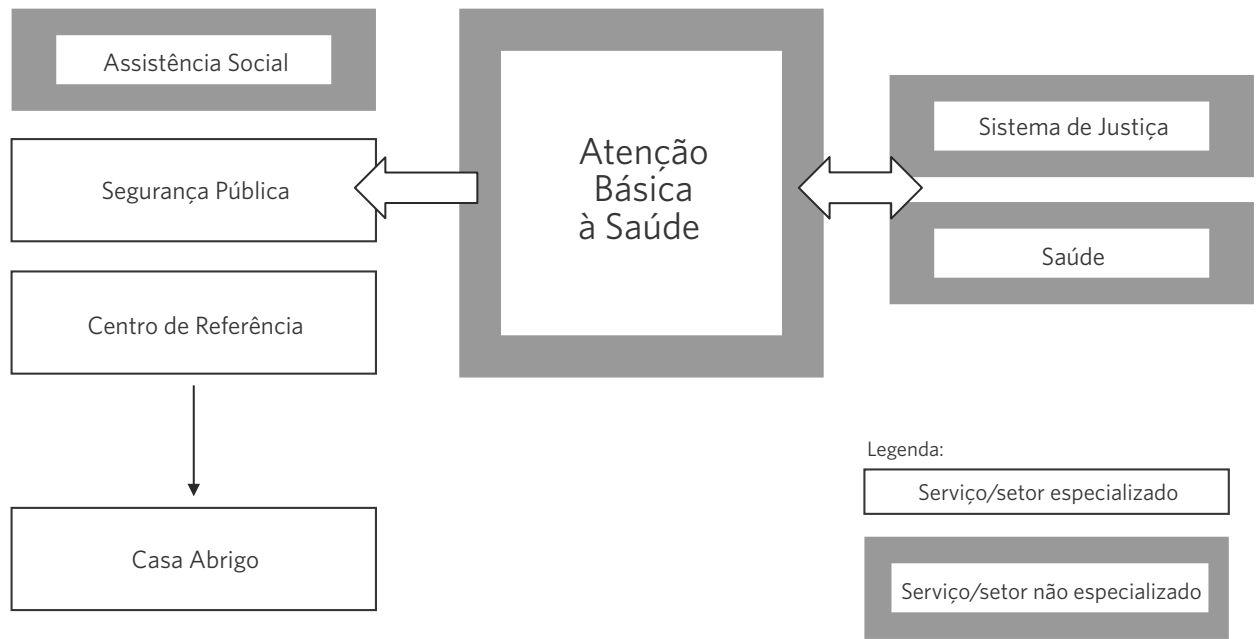

Fonte: Elaboração própria. 
Conforme o depoimento das entrevistadas, ao receber para o atendimento uma mulher em situação de violência, as profissionais das UBS relataram realizar encaminhamentos para serviços de assistência social, serviços especializados da segurança pública, centros de referência, serviços do sistema de justiça e outros serviços de saúde. Como se vê na figura, com estes dois últimos (sistema de justiça e saúde), há uma relação de reciprocidade nos encaminhamentos, em que as UBS também recebiam encaminhamento de mulheres em situação de violência que acessaram primeiramente esses outros serviços.

$\mathrm{Na}$ representação dos encaminhamentos entre as instituições, foram diferenciados os serviços especializados dos não especializados. Sobre os serviços não especializados para o atendimento a mulheres em situação de violência, temos a ABS que ocupa lugar central, dado que a figura foi construída, principalmente, a partir das entrevistas com as profissionais das UBS; a assistência social, como os Centros de Referência de Assistência Social (Cras) e os Centros de Referência Especializados de Assistência Social (Creas); sistema de justiça, como as defensorias públicas e os núcleos de aconselhamento jurídico; o setor saúde, serviços de atenção primária, secundária e terciária. Ainda sobre o setor saúde, as entrevistadas deram destaque para os encaminhamentos de mulheres em situação de violência para os serviços de saúde mental.

Sobre os serviços especializados no atendimento a mulheres em situação de violência, de que trata a presente figura, temos as casas abrigo, instituições especializadas para recepcionar mulheres em situação de risco por um período determinado; os centros de referência, que são organismos específicos e exclusivos para o atendimento e acompanhamento longitudinal a mulheres em situação de violência, no caso em questão ligados à política de assistência social, mas em outras regiões e em outros municípios há centros de referência ligados diretamente a estruturas governamentais de políticas para as mulheres municipais, governamentais e federal; e, por fim, o setor de segurança pública através das delegacias especializadas de atendimento à mulher.

Cabe destacar que não há um fluxo direto entre Casa Abrigo e UBS, pois o acesso às Casas Abrigo se dá através de avaliação de equipe técnica especializada dos centros de referência, em concordância com o fluxo nacional de abrigamento estabelecido ${ }^{19}$.

\section{Relação entre ABS e serviços especializados}

Foi possível verificar que a relação entre UBS e cada um dos serviços especializados no atendimento a mulheres em situação de violência se dava de forma diferente.

As entrevistadas do serviço policial relataram não haver o direcionamento de mulheres em situação de violência para UBS. As policiais apontaram para uma distância na relação do Especializadol com os serviços de saúde: "Não, Clínica de Família nunca vi, nunca recebi ninguém deles aqui...” (Entrevista EE3, p. 26).

Só esse mesmo, que é a questão de enviar para o médico, fazer o boletim de atendimento médico, depois ela volta à Delegacia, ou vai primeiro ao médico e já traz o BAM... tudo mais... Mas não é uma relação assim... íntima... [...] a única coisa que a gente pergunta - foi ao médico? -, - não foi ao médico?, tá, a gente vai fazer o registro do mesmo jeito -, - foi ao médico?, cadê o número do BAM -. Se a vítima estiver muito machucada vai, depois volta. Que às vezes ela está reclamando de dor de cabeça e não sei... pode acontecer alguma coisa. Mas... como eu te disse, quando elas vêm, nunca nenhuma chegou para mim e falou - não, foi o próprio médico, a própria enfermeira que disse para eu procurar a Delegacia -, vir aqui registrar, comigo. Comigo nunca procurou. (Entrevista EE2, p. 31).

As profissionais do serviço de orientação jurídica afirmaram que a relação com os serviços de saúde se dava de forma bastante pontual e as estagiárias entrevistadas salientaram não haver relação com os serviços de saúde, 
especialmente de atenção básica. De fato, este serviço não foi mencionado em nenhuma das entrevistas no campo da saúde como uma possibilidade de encaminhamento ou de parceria.

Algumas entrevistadas que atuavam no setor afirmaram realizar encaminhamentos para a atenção básica, considerando que a ABS constituía porta de entrada da Rede de Atenção à Saúde (RAS), assim, esse tipo de encaminhamento não era necessariamente para o trabalho de cuidado em saúde da mulher em situação de violência na atenção básica, mas para encaminhamento para outros níveis da atenção à saúde:

Normalmente é a Clínica da Família, né, porque a Clínica da Família que faz essa... que faz essa... por causa do SISREG, né... é a Clínica da Família que faz. (Entrevista EE8, p. 27).

Dos serviços especializados no atendimento às mulheres em situação de violência, a relação mais aproximada com as UBS se dava a partir dos centros de referência. Apesar das entrevistas das profissionais dos centros de referência mostrarem uma relação mais próxima com os serviços de saúde mental, que incluía espaços de estudos de caso interinstitucional e participação das profissionais dos centros nos rounds da saúde, as UBS, também, foram relacionadas como parceiras para o atendimento das mulheres em situação de violência.

O caso relatado a seguir, que trata de encaminhamento entre a UBS2 e o Especializado4, explicita essa relação de encaminhamento entre unidade básica e centro de referência:

Então, teve uma vez que recebi uma senhora, da área antiga ainda, que ela chegou desabando aqui... Ela chegou desabando e dizendo que o esposo dela era usuário de drogas, que ele bebia bebida alcoólica e que ele batia nela desde sempre, e que ela tem dois filhos e que os filhos dela ficam vendo aquilo e que ela... chegou aqui arrasada. Ea minha sorte foi que eu estava com uma residente... eu tinha acabado de chegar na unidade, então assim... eu não sabia muito bem os fluxos, para onde encaminhar essa mulher. Eu chamei a médica para fazer uma interconsulta, a médica passou uma medicação para ela, que ela falou que não estava conseguindo dormir, que ela não conseguia fazer nada... que ela só ficava chorando, já estava com um quadro depressivo... a gente encaminhou para o setor de psicologia que a gente tem aqui no $\mathrm{H}$ e a psicóloga... Não... era uma assistente social que estava aqui comigo... ela falou de um... do Especializado4, que tem aqui perto da nossa área, para ela ir lá, conversar... com as pessoas e tal... para a gente tentar fazer esse processo mesmo. (Entrevista ES28, p. 19).

As entrevistas apontaram para o centro de referência 'Especializado4' como o mais importante interlocutor entre a atenção básica e os serviços especializados de atendimento às mulheres em situação de violência da região. Uma das entrevistadas do Especializado4 fez o seguinte relato sobre atuação junto à UBS1:

A gente já fez até atendimentos juntos assim... para abrigamento, uma situação que eles perceberam de abrigamento e aí... Então... um caso de articulação de equipe e até extra... que foi bem sucedido. Eles atendiam uma moça que... [...] ...ela ia... porque ela ia para o atendimento de... Pré-natal... então acho que era o serviço... a enfermagem... com a ginecologista...era enfermagem e ginecologia a princípio mesmo, que atendia. E elas perceberam que a moça... às vezes ela ia acompanhada do marido, ele ficava do lado de fora assim, e ela entrava para consulta. Uma moça jovem... e aí algumas vezes ela chorou no atendimento e aí relatou, que ela vivia em situação de cárcere... então o cara não deixava ela sair para nada... ele acompanhava as consultas e ficava vigiando. Então, era de casa para... só fazia isso... só essas saídas vigiadas... que ela não aguentava mais, ela morava na casa da família dele... era todo... o tempo todo vigiada. Que ela tinha vontade de sair daquilo ali, mas ela não sabia como fazer.. parece que a família dela era de um outro estado. Aí essa equipe sugeriu... perguntou se não queria abrigamento, falou que não... que não ia fazer, que tinha medo dele... Mas aí depois assim... com 
algumas idas... ela disse que ela gostaria, mas que não sabia como fazer, porque ela tinha medo. Aí elas vieram aqui... contaram o caso e aí... [...] é, acho que foi a enfermeira mesmo com o ACS, que atendia... que é... acho que é aqui perto... ela morava aqui perto a menina... só que... sempre ia só com ele... Então... até quando ia na visita, que ela fazia visita, chegava lá e ele não deixava elas entrarem... uma coisa meio assim... E um casal jovem assim... Aí... ela marcou... contou para a gente e aí a gente combinou... tinha combinado com a menina, ela falou que era isso que ela queria, que ela queria sair e tal... E combinou na próxima consulta a gente ir até lá e de lá mesmo a gente esquematizar para que ela fosse para... abrigada. Aífoi feito assim... A gente foi para lá, esperou ela chegar, que aí não desconfiava que a gente estava lá, aí a gente fez o atendimento lá... preenchemos o pedido que precisava preencher, levantamos o resto da história e tudo mais. E aí de lá a gente levou ela para o abrigo... e aí... depois ela... a equipe do abrigo conseguiu encaminhá-la... acho que era do Espírito Santo... encaminhá-la para o abrigo, então assim... foi um trabalho junto com a equipe também de saúde, que conseguiu visualizar e tudo mais... e a gente conseguiu articular isso juntos. (Entrevista EE18, p. 27-29).

Essa prática de atendimento interinstitucional foi apontada como uma possibilidade, principalmente, em casos de necessidade de abrigamento de mulheres.

Encontramos neste relato de atendimento conjunto para a decisão de abrigamento um exemplo de superação de uma relação em trama de serviços para uma atuação em rede de serviços, tendo em vista que a partir da interação entre equipes de dois serviços (Especializado4 e UBS1), junto a uma mulher em situação de violência, as duas equipes, juntamente com a mulher, puderam decidir sobre as possibilidades de intervenção e encaminhamento para garantir a sua segurança e construir, em conjunto, caminhos de superação da situação de violência, portanto, um projeto assistencial comum.

Em suma, temos, então, algumas pistas de ações pontuais desenvolvidas de forma articulada entre os serviços, certo nível de interação entre algumas profissionais entre serviços específicos através do contato interinstitucional, do diálogo e das trocas. Todavia, ao serem questionadas sobre a relação entre os serviços de saúde de atenção básica e os serviços especializados, as afirmações das profissionais de ambos os campos revelaram o afastamento entre o setor saúde e os demais participantes de uma possível rede de atenção, resultado também encontrado em outras pesquisas sobre a temática $\mathbf{1 4 , 2 0 , 2 1}$.

Além dos encaminhamentos interinstitucionais, uma ação realizada entre os serviços de atenção básica e os serviços especializados diz respeito ao trabalho de capacitação em violência de gênero e rede de atendimento efetuado pelas profissionais da rede especializada em UBS.

EE18 apontou para atividades de palestras em unidades de saúde como um trabalho preventivo de violência. Afirmou que, no ano anterior, foram a alguns postos de saúde do entorno para falar sobre violência de gênero, atendimento à mulher em situação de violência e a rede de atendimento com as equipes de saúde.

Confirmando os relatos das profissionais dos centros de referência, uma profissional de saúde, 'ES31', afirmou que já participou de capacitação sobre violência de gênero no Especializado4.

\section{Lugar da ABS na atenção integral a mulheres em situação de violência}

Considerando que a mulher tem maior acesso à UBS que a outros serviços de atenção especializada, ou mesmo mais distantes de sua residência, as entrevistadas das UBS concordaram que a atenção básica constituiria a porta de entrada não só da RAS, mas também da rede especializada de atendimento às mulheres em situação de violência, corroborando os dados de pesquisa apresentados até aqui.

A violência, pela proximidade do território, possibilita muito... que muitos mais casos venham à luz... 
sejam atendidos... porque talvez essa mulher não vá ao DEAM, não vá ao CEAM... não vá a outros dispositivos, mas ela vem na Clínica para uma consulta. (Entrevista ES36, p. 20).

Porque é muito mais fácil a mulher chegar aqui... que está me vendo todos os dias, me conhece... já me chama pelo nome... me adiciona no facebook, então tem um vínculo muito maior para ela falar da violência do que ela chegar no hospital, com uma pessoa que ela nunca viu na vida e falar - ah, meu marido me bate-, de repente uma sala cheia de gente. Aqui eu acho que é um espaço muito mais fácil, por isso a gente notifica muito, às vezes, entendeu? Eu acho inacreditável quando às vezes uma Clínica não notifica, - gente, tem alguma coisa errada no acesso ou no vínculo -, porque imagina... se ela falar de violência... muito melhor falar com a pessoa que você está mais próxima, que você já chama pelo nome, tudo. Agora, chegar em um hospital... já trabalhei em hospital e vi situação de violência... [...] a mulher senta na sala e fala alto para todo mundo escutar, é muito difícil. (Entrevista ES35, p. 26).

Tais dados vão ao encontro do documento da Rede de Enfrentamento à Violência contra as Mulheres, da SPM-PR, que estabelece as UBS como parte desta rede de enfrentamento, como serviço não especializado, compondo a porta de entrada para os serviços especializados no atendimento às mulheres em situação de violência, e da literatura sobre o tema, como já especificado6-8,12,21. Mas ainda que a ABS seja uma porta de entrada privilegiada para os casos de violência, há grande dificuldade dos profissionais de saúde em lidar com a problemática da violência. De acordo com Diniz $^{8(31)}$, a saúde deve se responsabilizar por “[...] pelo menos identificar esses casos e referi-los adequadamente". Neste sentido, d'Oliveira e Schraiber22(135) afirmam:

[...] os profissionais nos serviços de saúde têm dificuldades para lidar com problemas como a violência, que são problemas mais identificados ao social e às normas culturais da sociedade ou identificados a comportamentos pessoais. São dificuldades que não se prendem apenas ao quê fazer, dentro de um leque de atuações bem delimitadas como intervenções sobre as doenças, mas dizem respeito, previamente, ao reconhecimento dessa situação de violência como pertinente ao campo de atuação em saúde.

Não obstante tal aspecto a argumentação de ES35 citada anteriormente traz uma similaridade com o que afirmam Menezes et al. ${ }^{7(784)}$ :

Nessa perspectiva, vale mencionar o papel dos profissionais que atuam na Estratégia de Saúde da Família (ESF), isso porque, na maioria das vezes, a Unidade de Saúde da Família (USF) se apresenta como porta de entrada para essas mulheres. Neste sentido, a equipe de Saúde da Família deveria aparecer como protagonista no processo de acompanhamento das mulheres em situação de violência, uma vez que trabalha com uma população adstrita, secundária ao processo de territorialização, o que permite um maior envolvimento com a comunidade, e consequentemente o reconhecimento e a compreensão de suas necessidades.

A presente pesquisa constatou que nas UBS2 e UBS1 prevaleceu o desconhecimento das profissionais sobre o trato com a questão da violência de gênero e as dificuldades de manejo quanto às possibilidades de encaminhamento dos casos para os serviços especializados, assim como apontam os estudos de Moreira et al. ${ }^{15}$ e Osis, Duarte e Faúndes ${ }^{\mathbf{2 3}}$.

ES22 afirmou que não havia aproximação da UBS1, em que atuava, com os serviços especializados de atendimento às mulheres em situação de violência e que não conhecia a rede para atendimento a mulheres em situação de violência, não saberia para onde encaminhar a mulher em situação de violência:

Mas eu não fui instrumentalizada... assim que fala, né?, eh... sobre esse fluxo de violência aqui na CAP 1.0. Eu não sei quais são as redes que a gente tem... como que a gente faz... o que eu posso... qual o 
apoio que eu posso oferecer? O que me vem imediatamente é a psicologia, o matriciamento... um momento para eu poder abrir e falar. (Entrevista ES22, p. 16).

ES20 disse que não era rotina encaminhar mulheres em situação de violência para outros serviços, por conta da violência.

P: no caso então, voltando um pouco à questão do atendimento à mulher em situação de violência... vocês costumam encaminhar a mulher em situação de violência para outros serviços?

R: não, por isso assim, não. (Entrevista ES20, p. 29).

ES20, também, afirmou que não conhecia os serviços de atendimento às mulheres em situação de violência e que não havia relação da UBS1 com os serviços de atenção às mulheres em situação de violência.

ES22 disse que não existia uma relação direta da UBS1 com os serviços de atendimento às mulheres em situação de violência.

Na UBS1, foi comum ouvir das profissionais de saúde que nunca atenderam mulheres em situação de violência.

De acordo com estudos já citados, podemos inferir que o não atendimento de mulheres em situação de violência pode estar mais relacionado à dificuldade da profissional de manejar a situação, de identificar a violência e lidar com o fato, do que à ausência das mulheres em situação de violência nas unidades básicas.

Concordamos com Berger ${ }^{24}$ que identificar a violência é diferente de rastrear uma doença. Considerando que a atenção em saúde para a questão da violência é insatisfatória, a autora discute os aspectos relacionados à formação profissional em saúde que ainda está fundamentado no modelo biomédico e os processos de trabalho em saúde centralizados no profissional médico. De acordo com a autora, essas questões constituem entraves para a atuação do campo da saúde na atenção às mulheres em situação de violência.

Borsoi et al. ${ }^{25}$ a partir de pesquisa realizada em duas unidades de ABS no município do Rio de Janeiro, apontam que as mulheres atendidas nos serviços que participaram da pesquisa vivenciam no cotidiano a violência doméstica e que, apesar de os profissionais identificarem a situação de violência, existe a dificuldade de lidar com a questão e efetuar encaminhamentos.

Não obstante estes aspectos, há que se destacar que na UBS3, unidade que mais notificava violência na Área de Planejamento, as equipes eram bastante sensíveis à questão da violência de gênero. De acordo com relatos, os casos de violência eram identificados e, com o apoio do Nasf e da gerência, as equipes manejavam os casos e contatavam serviços de outros setores de acordo com a necessidade da mulher. Como já apontado, o serviço especializado mais solicitado a atuar junto aos casos que chegavam na UBS3 era o centro de referência 'Especializado4'.

A presença do Nasf nesta unidade pode ser um fator facilitador para o reconhecimento de situações de violência e manejo dos casos. Como reconhecido na literatura, os profissionais de saúde da família consideram o Nasf um suporte importante para a lida com casos complexos no cotidiano, especialmente os relacionados à violência ${ }^{15}$.

Outro aspecto facilitador relevante pode ser o fato desta unidade ser uma unidade-escola, em que havia uma atuação orgânica de residência e suas preceptorias. $\mathrm{O}$ contato estreito com a universidade pode favorecer a capacitação profissional para lidar com os casos mais complexos de diferentes âmbitos que surgem no cotidiano. As outras unidades também contavam com apoio de residentes e graduandos, mas de forma mais periférica.

\section{Considerações finais}

A relevância do campo da saúde para a discussão sobre violência de gênero pode ser visibilizada, também, ao considerarmos a centralidade do conceito de integralidade, um dos princípios do SUS, para pensar sobre 
$o$ atendimento multiprofissional, interdisciplinar, intersetorial a mulheres em situação de violência, dada a complexidade da questão.

No campo da assistência, portanto, o conhecimento sobre as relações entre a ABS e os serviços especializados no atendimento às mulheres em situação de violência, no que se refere às potencialidades de trabalho em rede, faz-se necessário considerando a relevância do campo da saúde, especialmente da atenção básica, para a identificação dos casos de violência, o acolhimento dessas mulheres e as possibilidades de referência e contrarreferência com outros serviços de outros setores para o cuidado.

Não se pode questionar a efetiva preocupação da saúde no que se refere ao enfrentamento à violência contra as mulheres desde a década de $1980^{26}$. Como aponta Diniz ${ }^{8(30)}$, "um excelente exemplo de infiltração de gênero no desenvolvimento de respostas em violência contra a mulher no Brasil são as políticas de saúde".

Como salientam D'Oliveira e Schraiber ${ }^{22}$, muitas foram as conquistas no âmbito da implementação de serviços e da proposição de legislações voltadas para o enfrentamento à violência contra as mulheres, no entanto muitos são os obstáculos para que estas diversas instituições governamentais e não governamentais construam um mosaico inter-relacionado e bem articulado entre si, promovendo assim a assistência de qualidade às mulheres.

Consideramos, ainda, que privadas de seus direitos a uma atenção integral, as mulheres ficam sujeitas a outro tipo de violência de gênero: a violência institucional, compreendendo-se esta última também como uma crise em relações hierárquicas, mas neste caso da hierarquia entre profissionais da saúde e as mulheres usuárias desse serviço 27. Contudo, envolvendo a complexa relação hierárquica de autoridade técnico-científica, a violência institucional remete a questões bastante próprias e que devem ser mais aprofundadas em novos estudos.

A promoção da atenção integral a mulheres em situação de violência e sua concretização através de um trabalho multidisciplinar, interprofissional, intersetorial, em rede, demanda a ampliação de espaços de formação em saúde que versem sobre estes temas. A aproximação entre universidades e serviços de atenção à saúde da população pode ser um caminho exitoso, como apontam os dados da pesquisa. $\mathrm{E}$, ainda, consideramos potente a consolidação de projetos políticos que integrem profissionais de diferentes áreas a partir de uma perspectiva dialógica do cuidado.

O escopo da presente investigação pode ter grande valia para o cotidiano dos serviços e para provocar os profissionais e os serviços quanto às possibilidades de estabelecer espaços de diálogos para viabilizar a formação de redes.

A partir da proposta desta pesquisa, buscamos contribuir para a compreensão sobre a constituição das redes de atendimento às mulheres em situação de violência, bem como de que forma o campo da saúde interage com esses serviços, ampliando, assim, o conhecimento da saúde coletiva sobre a temática.

\section{Colaboradoras}

Gonsalves E (0000-0002-2170-2269)* e Schraiber LB (0000-0002-3326-0824)* contribuíram igualmente para a elaboração do manuscrito. 


\section{Referências}

1. Scott J. Gênero: uma categoria útil para análise histórica. Educ. realid. 1995; (20):71-99.

2. Saffioti H, Almeida SA. Violência de Gênero. Rio de Janeiro: Revinter; 1995.

3. Heise L, Ellsberg M, Gottemoeller M. Ending violence against women. Populat. Repor. 1999; XXVII(4).

4. Schraiber LB, Oliveira AFLP, Couto MT. Violência e saúde: contribuições teóricas, metodológicas e éticas de estudos da violência contra a mulher. Cad. Saúde Pública. 2009; 25 (supl 2):S205-16.

5. Schraiber LB, d' Oliveira AFPL, Falcão MTC, et al. Violência dói e não é direito. A violência contra a mulher, a saúde e os direitos humanos. São Paulo: Ed. UNESP; 2005.

6. Schraiber LB, d'Oliveira AFPL, França Junior I, et al. A violência contra mulheres: demandas espontâneas e busca ativa em unidade básica de saúde. Saúde e Soc. 2000 [acesso em 2021 mar 12]; 9(1/2):3-15. Disponível em: http://www.scielo.br/pdf/sausoc/v9n12/02.pdf.

7. Menezes PRM, Lima IS, Correia CM, et al. Enfrentamento da violência contra a mulher: articulação intersetorial e atenção integral. Saúde Soc. 2014 [acesso em 2021 fev 6]; 23(3):778-86. Disponível em: http://www. scielo.br/scielo.php?script=sci_arttext\&pid=S0104$-12902014000300778 \& \operatorname{lng}=$ pt\&nrm=iso\&tlng=pt.

8. Diniz SG. Violência contra a mulher: estratégias e respostas do movimento feminista no Brasil (19802005). In: Diniz SG, Silveira LP, Mirim LA, organizadores. 25 anos de respostas brasileiras em violência contra a mulher. São Paulo: Coletivo Feminista e Saúde; 2006. p. 15-44. [acesso em 2021 out 28]. Disponível em: https://www.mulheres.org.br/wp-content/uploads/2020/04/25anos-completo.pdf.

9. Krug EG, Dahlberg LL, Mercy JA, et al, editores. World report on violence and health. World Heal- th Organization: Geneva; 2002. [acesso em 2021 jan 16]. Disponível em: http://apps.who.int/iris/bitstream/10665/42495/1/9241545615_eng.pdf.

10. Schraiber LB, d'Olveira AFPL, Portella AP, et al. Violência de gênero no campo da saúde coletiva: conquistas e desafios. Ciênc. Saúde Colet. 2009; 14(4):101927.

11. Ayres JRCM. Organização das ações de atenção à saúde: modelos e práticas. Saúde Soc. 2009 [acesso em 2021 maio 12]; 18(supl2):11-23. Disponível em: http:// www.scielo.br/scielo.php?pid=S0104129020090006 00003\&script=sci_abstract\&tlng=pt.

12. Brasil. Secretaria de Política para as Mulheres. Rede de Enfrentamento à Violência contra as Mulheres. Brasília, DF: SPM; 2011. [acesso em 2021 fev 12]. Disponível em: https://wwwl2.senado.leg.br/institucional/omv/entenda-a-violencia/pdfs/rede-de-enfrentamento-a-violencia-contra-as-mulheres.

13. Fausto MCR, Almeida PF, Bousquat A. Organização da atenção primária à saúde no Brasil e os desafios para a integração em redes de atenção. In: Mendonça MHM, Matta GC, Gondim R, et al., organizadores. Atenção primária à saúde no Brasil: conceitos práticas e pesquisa. Rio de Janeiro: Ed. Fiocruz; 2018. p. 51-72.

14. d'Oliveira AFPL, Schraiber LB, Hanada H, et al. Atenção integral à saúde de mulheres em situação de violência de gênero: uma alternativa para a atenção primária em saúde [periódico na internet]. Ciênc. Saúde Colet. 2009 [acesso em 2021 fev 2]; 14(4):103750. Disponível em: http://www.scielo.br/scielo. php?pid=S1413-81232009000400011\&script $=$ sci abstract\&tlng=pt.

15. Moreira TNF, Martins CL, Feuerwerker LC, et al. A construção do cuidado: o atendimento às situações de violência doméstica por equipes de Saúde da Família. Saúde Soc. 2014; (23):814-827. 
16. Schraiber LB, d'Oliveira AFPL, Hanada H, et al. Assistência a mulheres em situação de violência - da trama de serviços à rede intersetorial. Athenea Dig. 2012; 12(3):237-254.

17. Gonsalves EN. As relações entre a atenção básica à saúde e os serviços especializados no atendimento a mulheres em situação de violência: um estudo de caso sobre as potencialidades de rede. [tese]. São Paulo: Universidade de São Paulo; 2019.

18. Bardin L. Análise de conteúdo. Tradução de Luís Antero Reto, Augusto Pinheiro. São Paulo: Edições 70; 2011.

19. Brasil. Secretaria de Políticas para as Mulheres. Diretrizes Nacionais para o Abrigamento de Mulheres em Situação de Risco e Violência. Brasília, DF: SPM; 2011. [acesso em 2021 mar 15]. Disponível em: https:// www12.senado.leg.br/institucional/omv/entenda-a-violencia/pdfs/diretrizes-nacionais-para-o-abrigamento-de-mulheres-em-situacao-de-risco-e-de-violencia.

20. Rolim KI, Falcke D. Violência conjugal, políticas públicas e rede de atendimento: percepção de psicólogos(as). Psic. Cienc. e Profissão. 2017 [acesso em 2021 maio 10]; 37(4):939-55. Disponível em: http://www.scielo.br/pdf/pcp/v37n4/1414-9893pcp-37-04-0939.pdf.

21. Silva EB, Padoin SMM, Vianna LAC. Mulher em situação de violência: limites da assistência.. Ciênc. Saúde Colet. 2015 [acesso em 2021 jan 18]; 20(1):249-58. Disponível em: http://www.scielo.br/pdf/csc/v20nl/ pt_1413-8123-csc-20-01-00249.pdf.

22. d'Oliveira AFPL, Schraiber LB. Mulheres em situação de violência: entre rotas críticas e redes intersetoriais de atenção. Rev Med. 2013 [acesso em 30 abr. 2021]; 92(2):134-40. Disponível em: http://www.revistas.usp.br/revistadc/article/view/79953/83887.
23. Osis MJD, Duarte GA, Faúndes A. Violência entre usuárias de unidades de saúde: prevalência, perspectiva e conduta de gestores e profissionais. Rev saúde pública. 2012 [acesso em 2021 mar 15]; 46(2):351-52. Disponível em: http://www.scielo.br/scielo.php?script=sci abstract\&pid=S0034-89102012000200018\&lng=e\& tlng=pt.

24. Berger SMD. Violência entre parceiros íntimos: Desafios no ensino e atenção em saúde. Rev Bras Ed Médica. 2011; 35(4):526-534.

25. Borsoi TS, Brandão ER, Cavalcanti MLT. Ações para o enfrentamento da violência contra a mulher em duas unidades de atenção primária à saúde no município do Rio de Janeiro. Interface (Botucatu). 2009 [acesso em 2021 fev 15]; 13(28):165-74. Disponível em: http://www.scielo.br/scielo.php?pid=S1414$-32832009000100014 \&$ script=sci_abstract\&tlng=pt.

26. Silveira LP. Serviços de atendimento a mulheres vítimas de violência. In: Diniz SG, Silveira LP, Mirim LA, organizadores. Vinte e cinco anos de respostas brasileiras em violência contra a mulher: alcances e limites. São Paulo: Coletivo Femin e Saúde; 2006. p. 45-77 [acesso em 2021 fev 12]. Disponível em: http://www.mulheres.org.br/site/wp-content/ uploads/2012/05/25anos-completo.pdf.

27. Aguiar JM, Azeredo YN, d'Oliveira AFPL, et al. Violência institucional, direitos humanos e autoridade tecno-científica: a complexa situação de parto para as mulheres. Interface (Botucatu). 2020; (24):e200231.

Recebido em 15/05/2021

Aprovado em 06/10/2021

Conflito de interesses: inexistente

Suporte financeiro: não houve 